\title{
Breve Ensaio sobre Estudos de Defesa como Atividade Científica
}

\section{Brief Essay on Defense Studies as a Scientific Activity}

Rev. Bra. Est. Def. v. 2, no 2, jul./dez. 2015, p. 21-28

EUGENIO DINIZ

Quando se propõe uma discussão epistemológica, frequentemente pensa-se em Filosofia da Ciência e nas discussões correlatas: o que distingue Ciência de outras formas de conhecimento e de reflexão; se há ou não algo como método científico, e o que o distinguiria; problemas como falseabilidade, demarcação, corroboração; e outras bastante conhecidas. Mas este conjunto é apenas uma parte, dentre muitas outras, da discussão epistemológica, e seguramente não é o que nos interessa aqui, em que se trata de responder a um convite para discutir "a dimensão epistêmica da Defesa”. Parece-me que o mais relevante aqui é tentar identificar o que caracteriza os Estudos de Defesa como atividade científica. Antes, uma observação: para evitar a possibilidade de confusão em situações em que o termo "Defesa" poderá ser empregado, ao longo do texto, em referência a outras coisas que não à atividade científica de que se trata aqui, referir-se-á a esta última como "Estudos de Defesa" - como, de resto, é frequente na literatura em inglês (Defence Studies ou Defense Studies, dependendo do país). Mas isso apenas por comodidade: não se trata de nenhuma tomada de posição.

Começando pelo que é bem sabido, cabe lembrar que, entre os gregos, quando se pensava no problema epistêmico, tratava-se de diferenciar entre o conhecimento rigoroso e embasado e aquilo que fosse uma mera opinião ou palpite — no sentido em que hoje falamos, informalmente, de "achismo”, e não no sentido de uma avaliação solidamente construída de questões sobre as quais pesam doses consideráveis de incerteza e de diferenças 
valorativas. Se, contemporaneamente, tratar de questões epistêmicas consolidou-se predominantemente na discussão do que constitui o que modernamente chamamos de "Ciência", por outro lado, isso está longe de esgotar o assunto.

No que concerne mais diretamente ao tema da nossa discussão — os aspectos epistêmicos dos Estudos de Defesa - , eu o poria nos seguintes termos: qual o lugar da Defesa como objeto de estudo? Devemos falar de uma "Ciência da Defesa" ou de uma "discussão cientificamente instruída sobre problemas de Defesa”? O ponto é que, claramente, é possível fazer uma discussão cientificamente instruída sobre assuntos de defesa - na verdade, é possível discutir-se cientificamente sobre praticamente qualquer coisa; falar de uma "Ciência da Defesa”, por outro lado, é claramente inapropriado. Passemos à argumentação, começando por aquilo que os Estudos de Defesa, como atividade científica, não são.

Uma observação: a agregação e a distinção entre atividades científicas se dará em grossas pinceladas, carregando nas tintas, para simplificar a discussão e torná-la mais prática. Não se trata de afirmar categoricamente que esta ou aquela disciplina, mencionada ao longo do texto, conforme-se, ou deva conformar-se, à sumária descrição aqui feita. Temos certeza de que, a rigor, nenhum dos membros das comunidades científicas das ciências ou disciplinas mencionadas considerará que a caracterização aqui feita reflete exatamente o que fazem, e nem é esta a intenção nesse ensaio. Trata-se apenas de avaliar e apontar caminhos para a comunidade científica que se debruça sobre problemas de Defesa, a partir de uma descrição muito sumária dos caminhos existentes. Como já ressaltado, não se trata de nenhuma reflexão mais formalizada do ponto de vista epistemológico.

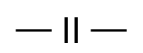

Em primeiro lugar, não se pode falar em uma "Ciência da Defesa” no mesmo sentido em que se reconhecem ciências como, por exemplo, Física, Química, Biologia, Sociologia. Estas são ciências facilmente reconhecíveis como tal: têm cara de ciência, jeito de ciência, nariz de ciência, boca de ciência, orelha de ciência e andam como ciência. Ou seja, a atividade científica focada na identificação de hipóteses sobre relacionamentos entre fenômenos - com destaque para relações de causalidade, mas não necessariamente se resumindo a estas - no teste dessas hipóteses, sua reformulação e sistematização em teorias de alcance mais amplo, incluindo mais fenômenos sob um mesmo marco conceitual, etc. Em larga medida, os fenômenos e relações que estudam são fundamentais, com fortíssimas implicações 
sobre outros fenômenos, ou sobre outras relações entre fenômenos, que eventualmente são estudados ou explorados em outras disciplinas, ou por outras disciplinas - como no caso da dependência das Engenharias principalmente, mas não apenas, para com a Física, ou como da Medicina e da Veterinária para com a Biologia, por exemplo. Claramente, não vejo como falar apropriadamente de "Ciência da Defesa" nesses mesmos termos.

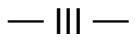

Em segundo lugar, não me parece apropriado tratar Estudos de Defesa do mesmo modo como geralmente referimo-nos às Engenharias, Medicina, Administração ou, de um modo mais peculiar, o Direito, como atividades científicas. Nesses ramos de atividade científica, trata-se em larga medida de integrar contribuições, abordagens, teorias, evidências, conclusões e insights provenientes muito frequentemente de outras disciplinas - e particularmente daquelas mencionadas logo acima - , com o foco direcionado para o enfrentamento de problemas muito concretos, e que, por sua vez, gera muitos problemas novos em termos de conhecimento, o que as torna muito fecundas com relação àquelas disciplinas, digamos, mais originais. Outra característica desse grupo de atividades científicas é que elas tendem a interagir fortemente entre si - ainda que haja maior afinidade entre algumas delas. Por exemplo, a Medicina interage intensamente com vários setores das Engenharias, no que concerne a técnicas e equipamentos para exames, procedimentos, tratamentos, etc.; talvez o exemplo mais impactante seja a crescente importância da tecnologia nuclear para tratamentos e diagnósticos, mas os exemplos são legião. Igualmente ilustrativa é a relação entre a pesquisa de fármacos e os diversos ramos e sub-ramos da Química - Química Orgânica, Química do Organismo Humano, etc.

Mas o caso das Engenharias é também bastante ilustrativo, especialmente no que concerne aos Estudos de Defesa. O desenvolvimento e a institucionalização das Engenharias estão fortemente relacionados ao desenvolvimento da Artilharia: o desenvolvimento de novas fortificações, que pudessem resistir à nova Artilharia, dependeu intensamente da aplicação de Matemática - as fortificações concebidas por Vauban são o exemplo histórico mais significativo. O exemplo é marcante porque sua importância histórica é enorme: quando se estuda, em História, a famosa "aliança entre o Rei e a burguesia”, frequentemente se deixa de lado o porquê de o Rei precisar do dinheiro da burguesia. O ponto é que dispor simultaneamente desses dois tipos de recursos - artilharia que derrubaria antigas fortificações e a construção de novas fortificações que permitissem enfrentar forças equipadas com as peças de artilharia de sítio, garantindo assim o controle 
de áreas que eram tomadas aos demais senhores feudais - exigia riquezas que estavam além das disponíveis para os senhores feudais, dos quais o Rei era apenas um primum inter pares, mas cuja primazia era vantagem suficiente para que fosse o mais útil beneficiário potencial da aposta dos comerciantes na unificação política, fiscal e monetária de grandes espaços geográficos. Ou seja, pode-se arguir que, sem as Engenharias e sua relação com a Matemática, não haveria os Estados Nacionais como os conhecemos.

Outro exemplo recente, bastante interessante, é o caso da Engenharia de Produção. Dentre os problemas típicos dessa área, está o de integrar espaços, instalações, equipamentos, infraestrutura, pessoas e procedimentos para a viabilização de uma determinada função de produção. Desse modo, algumas outras áreas são de forte interesse para a Engenharia de Produção, como, por exemplo, Ergonomia e Fisiologia do Trabalho, que, por sua vez, interagem fortemente com Mecânica, Óptica, Biologia, Física de Materiais, entre outras; as pesquisas relacionadas a Logística, por sua vez, interagem intensamente com Mecânica, Geografia, Geologia, Economia, etc.; mas, ainda mais ilustrativa para nossos propósitos, é a Pesquisa Operacional - ramo típico da Engenharia de Produção - , que se relaciona estreitamente com Matemática, Estatística, Logística, Mecânica, Eletrônica, entre outras: a Pesquisa Operacional surge para, literalmente, encontrar submarinos alemães durante a Segunda Guerra Mundial. Ainda assim, trata-se claramente de Engenharia - ainda que aplicada à solução de problemas relacionados à Defesa —, e não de Estudos de Defesa como tal.

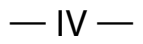

Também não me parece adequado falar de uma "Ciência da Defesa" no mesmo sentido em que, por exemplo, Economia, Meteorologia, Ecologia, Ciência Política ou História - esta última com alguns aspectos bem próprios - são ciências. Em tais disciplinas, os fenômenos a serem estudados são articulados em torno dos processos a que se visa compreender: no caso da Economia, as interações relacionadas aos processos de produção, circulação, distribuição da riqueza socialmente produzida, enfim, processos pelos quais as sociedades produzem o atendimento de suas necessidades materiais; no caso da Ciência Política, interações relacionadas à produção de regras e expectativas, formais ou informais, de gestão da vida coletiva, de atribuição de responsabilidades e de prerrogativas, de divisão de benefícios e custos das ações coletivas.

Além da Economia, da Ciência Política e das demais disciplinas citadas acima, creio que dois outros campos do saber que nos interessam mais diretamente pertencem a este grupo: Relações Internacionais, de um la- 
do, e Estudos Estratégicos, de outro. No caso de Relações Internacionais, trata-se de compreender os processos pelos quais coletividades, independentemente de sua forma organizacional ou jurídica, estabelecem, mantêm, administram e modificam algum tipo de modus vivendi; no caso dos Estudos Estratégicos, trata-se de compreender os processos relacionados à gestão do emprego ou da possibilidade do emprego da força física como parte do relacionamento entre indivíduos, entre grupos, entre coletividades, seja na garantia ou na transformação da regulamentação do convívio no interior de uma dada sociedade, seja na manutenção ou transformação do modus vivendi entre coletividades - transformação que pode ser tão radical que culmine com a erradicação de uma, ou mais de uma, delas, incluindo, como possibilidade, a aniquilação mútua.

Cabe aqui um pequeno desvio: tanto as nossas experiências quanto as nossas linguagens nos levam a pensar que tanto Estudos Estratégicos quanto Relações Internacionais estariam relacionados exclusivamente a seres humanos - e o "nacionais" que constitui "Internacionais" enfatiza essa vinculação. Rigorosamente, falando, entretanto, isso é inapropriado. Eu começo minhas aulas de Estudos Estratégicos no curso de graduação em Relações Internacionais exibindo dois pequenos vídeos. O primeiro mostra uma águia disputando território (isso mesmo, território) com outra águia, ambas competindo por altitude - maior altitude significa maior energia potencial que, na medida em que a águia desce, converte-se progressivamente em energia cinética - , de modo a tentar obter vantagem energética ao agarrar a outra pelas patas e fazê-la girar para, em seguida, arremessá-la ao chão, um penhasco ou uma outra superfície rígida, maximizando a energia do impacto: isso é claramente um fenômeno típico de Estudos Estratégicos. O outro vídeo mostra um bando de chimpanzés discretamente invadindo (emprego esse termo deliberadamente) em formação o território (emprego também esse termo deliberadamente) habitado por outro bando de chimpanzés, evitando fazer ruídos que denunciem sua presença, destacando batedores que tentam localizar onde o outro bando estava, até que, encontrando-o, os invasores iniciam um assalto coordenado, com desfecho trágico para os assaltados; trata-se de fenômeno típico de Estudos Estratégicos e, nos seus elementos fundamentais, também de Relações Internacionais - por mais inapropriado que seja referirmo-nos a bandos de chimpanzés como "nações"; mas isso é um problema da nomenclatura "relações internacionais".

Mas, como somos humanos, interessamo-nos mais quando abordamos esses fenômenos quando humanos estão envolvidos. Mais uma vez, o hábito e a praticidade nos levam a associar mais frequentemente Estudos Estratégicos a Relações Internacionais; entretanto, inúmeras atividades, ações, operações policiais não só podem como deveriam ser analisadas a partir das categorias, 
conceitos e relacionamentos próprios dos Estudos Estratégicos - assim como disputas entre gangues ou brigas de rua. $\mathrm{O}$ ponto que quero fazer a partir disso é o seguinte: apesar da também óbvia afinidade mútua, Estudos Estratégicos e Estudos de Defesa são atividades distintas.

Mas, além disso, como dito anteriormente, Estudos de Defesa - assim como Estudos de Segurança Pública, por exemplo — não constituem um tipo de atividade científica como as que mencionamos anteriormente. Diferentemente de Relações Internacionais, Estudos Estratégicos, Ciência Política ou Economia, entre outras, os Estudos de Defesa não estão voltados à compreensão de um conjunto de fenômenos e interações articulados em torno de determinados processos.

\section{$-\mathrm{V}-$}

Onde entram, então, os Estudos de Defesa? Que tipo de atividade científica a gente tem em mente? Quando penso em Estudos de Defesa, penso na mobilização de um conjunto de conhecimentos provenientes de outros campos, de modo a enfrentar alguns tipos de problemas muito práticos relacionados às atividades de defesa.

No meu entendimento, quando falamos de Estudos de Defesa, temos em mente, na verdade, problemas relacionados a políticas de defesa. Comecemos pelo eufemismo "defesa”. Não creio que ninguém pense que haveria duas áreas distintas: Estudos de Defesa e Estudos de Ataque. Fala-se de Estudos de Defesa porque há os Ministérios da Defesa, ou seus equivalentes — ou mesmo, se se trata de Ministérios separados, como era o caso no Brasil há alguns anos, há o conjunto de problemas associados à gestão das Forças Armadas - , que, por razões de sensibilidade política, não são chamados de Ministérios da Guerra e muito menos de Ministérios do Ataque.

Além disso, quando se pensa em Estudos de Defesa, pensa-se em muitas outras coisas além dos processos e necessidades relacionados a "defender" e/ou "atacar" (que, aliás, são problemas típicos de Estudos Estratégicos, obviamente relacionados a Estudos de Defesa, mas distintos): pensa-se em Relações Internacionais, por motivos óbvios; pensa-se em Relações Civis-Militares e em Sociologia das Forças Armadas — que, pode-se arguir, é quase uma aplicação de Sociologia das Organizações, mas que inequivocamente é, bem, Sociologia; pensa-se em Economia de Defesa - que é Economia; pensa-se em Logística, já mencionada anteriormente; necessariamente, não há como não pensar em Estudos Estratégicos, como já mencionado; pensa-se, enfim, em muitas disciplinas diversas, mas aplicadas ou mobilizadas para a discussão cientificamente informada de problemas típicos de política de defesa. E, finalmente, como no caso, por exemplo, de 
Políticas Públicas, cuja afinidade com a Ciência Política é evidente — apesar de envolver tantas outras disciplinas - os Estudos de Defesa, não obstante envolvam muitas disciplinas distintas, têm uma vinculação evidente a Relações Internacionais: afinal, quando se pensa em Defesa, pensa-se na defesa contra a ação de outrem, de outra coletividade, de outra sociedade, de outro país, de outro Estado, ou até mesmo de grupos em outros Estados ou grupos com presença transnacional. A situação pode ser comparada com, por exemplo, os estudos de Segurança Pública: claramente pode-se fazer, e faz-se, discussão cientificamente informada sobre problemas de Segurança Pública; várias disciplinas envolvidas na discussão são bastante parecidas com o que ocorre em Defesa - disciplinas de Sociologia, de Administração, Estudos Estratégicos, por exemplo; outras serão bem mais específicas - sendo Criminologia um exemplo bastante conspícuo; mas aqui, novamente, a afinidade é muito maior com Políticas Públicas, ou mesmo com Administração Pública, e não com Relações Internacionais. Já Defesa, claramente, sofre muito mais intensamente o peso das Relações Internacionais nas suas considerações.

Parece-me que é nesses termos que devemos entender a dimensão epistêmica dos Estudos de Defesa: deve-se pensar nela como uma atividade de discussão cientificamente instruída, voltada para a compreensão e enfrentamento de problemas ligados a políticas de defesa, mobilizando, para tanto, diversas disciplinas e direcionando-as para o tratamento daqueles problemas específicos, mas com uma afinidade particularmente intensa com Relações Internacionais. 


\section{BREVE ENSAIO SOBRE ESTUDOS DE DEFESA COMO ATIVIDADE CIENTÍFICA}

\section{RESUMO}

O presente ensaio está voltado para uma caracterização dos Estudos de Defesa como Atividade Científica, a partir de um contraste com outras áreas. Conclui-se que os Estudos de Defesa, como atividade científica, caracterizam-se pela mobilização de um conjunto de conhecimentos provenientes de outros campos, de modo a enfrentar alguns tipos de problemas muito práticos relacionados às atividades de defesa.

Palavras chave: Defesa; Ciência; Relações Internacionais; Ciência Política.

\section{ABSTRACT}

This essay focuses on characterizing Defense Studies as scientific activity, by contrasting it with other disciplines and areas of knowledge. The conclusion is that the scientific activity we call Defense Studies is best characterized by the mobilization of knowledge from other fields, in order to address some very practical problems related to defense-policy activities.

Key-words: Defense; Science; International Relations; Political Science. 